\title{
Urgences
}

\section{L'histoire du petit nuage}

Denuis Saint-Yves

Numéro 8, 4e trimestre 1983

Littérature jeunesse

URI : https://id.erudit.org/iderudit/025117ar

DOI : https://doi.org/10.7202/025117ar

Aller au sommaire du numéro

Éditeur(s)

Urgences

ISSN

0226-9554 (imprimé)

1927-3924 (numérique)

Découvrir la revue

Citer ce document

Saint-Yves, D. (1983). L'histoire du petit nuage. Urgences, (8), 35-42.

https://doi.org/10.7202/025117ar

Ce document est protégé par la loi sur le droit d'auteur. L’utilisation des services d'Érudit (y compris la reproduction) est assujettie à sa politique d'utilisation que vous pouvez consulter en ligne.

https://apropos.erudit.org/fr/usagers/politique-dutilisation/
Cet article est diffusé et préservé par Érudit.

Érudit est un consortium interuniversitaire sans but lucratif composé de l’Université de Montréal, l'Université Laval et l'Université du Québec à Montréal. Il a pour mission la promotion et la valorisation de la recherche. https://www.erudit.org/fr/ 


\section{DENUIS SAINT-YVES}




\section{L'HISTOIRE DU PETIT NUAGE}

il était une fois un petit nuage qui n'en menait pas bien large il était tout petit tout petit ô si petit qu'il fallait s'y prendre à deux fois pour le bien voir jamais une goutte de pluie ne s'échappait de lui ce qui le rendait très triste sans qu'il puisse cependant le faire voir autour de lui un grand ciel bleu lui faisait des sourires mais notre petit nuage ne sachant pas lire sur les lèvres ne savait que répondre et il détournait obstinément la tête vers en bas

où une singulière planète se tenait comme par enchantement et c'était une autre chose qui venait s'ajouter à son chagrin car il voulait y aller faire un tour histoire de changer de paysage

un jour

que le petit nuage était en train de regarder la terre et que son petit coeur brûlait sans pour autant se consumer un grand vent se leva

un vent comme il n'en avait jamais vu un vent auquel il ne pouvait résister il était malgré lui entraîné dans une course folle lorsque soudain au loin il aperçut d'autres nuages mais bien plus gros que lui il n'eut pas le temps de réaliser ce qui se passait qu'il se retrouva pris entre deux énormes nuages qui le trouvèrent si mignon qu'ils décidèrent sur le coup de le prendre avec eux le petit nuage se retrouva bien vite dans le ventre de l'un d'eux mais ce même jour il arriva ce qui forcément devait arriver La pluie 
car les gros nuages étaient heureux à en pleurer d'avoir avec eux un si mignon petit nuage alors

le petit nuage pour un moment s'évanouit quand il se réveilla un peu de lui se trouvait sur l'herbe et le reste dans le ruisseau il noua très vite des rapports de bon voisinage avec tout ce qui se trouvait sur cette singulière planète

depuis ce jour

la terre et l'eau sont devenues ses amies et de temps en temps quand le ciel lui sourit il y retourne faire un tour pour apprendre son langage sachant que tôt ou tard il reviendra sur terre 


\section{LE PETIT BONHOMME}

bien connu

sous le nom du Petit Bonhomme

il allait le jour durant

donnant à chaque personne qu'il rencontrait un gentil mot soit par politesse

soit par tendresse

...

il passait ainsi le plus clair de son temps

à distribuer ses mots qu'il avait bien pris soin de polir comprendre et rassurer

afin qu'ils puissent toucher le coeur et l'esprit

de ceux qui les recevaient

...

certains le regardaient d'un air inquiet

en le traitant de petit mendiant

et même parfois de petit insolent voulant leur apprendre

des choses en retour de quelque privilège imaginaire

d'autres lui tendaient gauchement quelques sous

afin qu'il s'achète des bonbons

ou des chaussures selon le besoin

$\ldots$

c'était là son monde

un monde fait de contrastes

(pour contrarier dirions-nous)

et qu'à cela ne tienne

il s'en accommodait sans juger les personnes qu'il rencontrait laissant cette tâche ingrate à d'autres

qui semble-t-il étaient doublement mieux préparés que lui

pour ce genre de Choses

il allait beau temps mauvais temps

avec ses gentils mots qu'il distribuait

sans penser que cela pouvait s'épuiser

et chose étrange il trouvait là sa richesse

à dépenser sans compter

se disant en lui-même que bien malin

serait celui qui lui ferait observer le silence 
un matin

comme il se préparait à partir

pour l'école de la vie

il s'aperçut qu'il n'avait plus de voix

qu'elle s'était sans doute éteinte paisiblement

au milieu de la nuit

et cela lui importait davantage que les autres malaises

qu'il sentait confusément vouloir se glisser

dans son corps

et comme il n'était pas tout à fait médecin

il ne pensa pas un instant que cette épreuve

pouvait être le résultat de ses nuits passées

à la belle étoile

à chanter

à rire avec le vent

à dormir au gré de sa fantaisie

dans un champ bien emmitouflé de foin

un fossé un arbre et même parfois dans une grange

il se recoucha

pensant que c'était là un bien mauvais rêve

que tantôt il se réveillerait bien portant

et que ses petites lèvres répondraient à nouveau

lorsqu'il les appellerait

mais le destin en voulut tout autrement

et il s'endormit pour ne se réveiller que dans le pays

du bon Dieu

la nouvelle de la mort du Petit Bonhomme

se répandit comme une frange de poudre

et chacun sentant en lui résonner le remords

vint lui rendre un gentil mot

(aujourd'hui on dit plus volontiers un hommage)

si bien qu'à la fin voyant le nombre incroyable de mots

qui reposaient à ses côtés

et qui à tout moment pouvaient se perdre

un vieux monsieur décida de les réunir

de les noter bien soigneusement dans un grand livre 
on fit de longues recherches

pour trouver le véritable nom du Petit Bonhomme afin de l'inscrire sur sa pierre tombale mais on ne parvint après maints efforts qu'à dénicher son prénom

et l'on imagina l'épitaphe suivant

Cl-GIT

LE PETIT ROBERT

L'AMOUREUX DES MOTS

encore aujourd'hui Dieu sait comment I'on entend parler du Petit Bonhomme 


\section{L'HISTOIRE DU MĖCHANT PETIT POĖME}

il était une fois

un poème qui se sentait très triste parce que personne

ne voulait le lire

il est vrai

que c'était un poème style désespérant

mais quand même de là à ce que pas même

un petit enfant ne consente à le lire

il y avait tout un monde

un jour

qu'il se sentait encore plus seul

que les autres jours Dieu sait pourquoi

il se mit à faire le beau

à tendre la patte

dans l'espoir qu'on le lise

et qui sait qu'on l'adopte

il voulait tant se rendre utile à quelque chose

et comme le hasard fait bien les choses

un gros monsieur qui passait par là

échappa ses lunettes justement sur le pupitre

où se tenait le poème en question

si bien qu'en ramassant ses lunettes

il se trouva en présence du poème

qui lançait à tue-tête

des petits "ô ô monsieur lisez-moi"

je vous en supplie cela me ferait le plus grand bien

alors

le gros monsieur se sentit ému jusqu'aux larmes

possédé de quelque démon dirions-nous

si bien qu'il lut le poème d'un bout à l'autre

sans prendre le temps de souffler

quand il eût fini

il essuya de sa joue mille petites larmes

il remit le poème à sa place

et s'en alla sur la pointe des pieds

en espérant que le poème s'endormirait

et le laisserait tanquille

mais le poème maintenant qu'il savait 
ce que c'est que d'être lu

criait au gros monsieur de ne pas l'abandonner

depuis ce jour

le gros monsieur va l'âme en peine

on le dirait à la dérive sur un bien frêle radeau

et le méchant petit poème (il faut bien dire

la même comme elle se présente)

ne sachant le mal qu'il a fait

se console à la pensée qu'il fût serviable

à quelque chose au moins une fois

dans sa vie 